\title{
Analysis of Optical Efficiency in Heliostat Field Layout with Various Separation Distance
}

\author{
Lai Lai Wah ${ }^{1}$, Wunna Swe ${ }^{2}$, Thin Thin Lwin ${ }^{3}$ \\ Department of Electrical Power Engineering \\ Mandalay Technological University \\ Mandalay \\ Myanmar
}

\begin{abstract}
The main aim of this paper is to design the heliostat field layout of solar thermal generation for a concentrated solar tower power plant, based on the central power tower technology. In this design, the radial staggered pattern is proposed to reduce shadowing and blocking losses. The radial stagger arrangement is the most efficient for a given land area as it cuts down the land usage and atmospheric attenuation losses. By using this pattern, the heliostat can be placed with higher optical efficiency as well as a faster speed due to the fact that each heliostat could move freely and the heliostats standing between two heliostats of the first ring reduce the shadowing and blocking. The field layout consists of 650 heliostats around a $62 \mathrm{~m}$ tall tower and each heliostat has a $121 \mathrm{~m} 2$ reflecting area. The power plant is designed to produce an output of $30 \mathrm{MWth}$ thermal power with the molten salt storage system. The optical efficiency is calculated by the product of the mirror reflectivity, the atmospheric attenuation efficiency, the shadowing and blocking efficiency and the cosine efficiency. The available separation distance of attenuation efficiency is evaluated the optical efficiency. The separation distance of the attenuation efficiency is less; the optical efficiency of the field layout is more. The separation distance of the attenuation efficiency is increased; the heliostat field area of the layout is also increased. By varying the separation distance between the heliostats is achieved the optical efficiency and the heliostat field area for under different conditions. The input data are assigned in MATLAB for testing this proposed method.
\end{abstract}

Keywords: Attenuation Efficiency, Cosine Efficiency, Heliostat Field Layout, Optical Efficiency, Radial Staggered Pattern.

\section{INTRODUCTION}

Concentrated solar power (CSP) technologies are relied upon to lead the power generation in the future in many countries. Among CSP technologies, central receiver system (CRS) or central power tower is an alluring method to accomplish immensely enormous power and high concentration of solar irradiance for electricity generation or thermal processes. Central receiver system consists of a high sun -tracking mirror number which concentrates solar radiation at a focal point located on the top of a high tower. The heliostat field is the focal subsystem in the solar tower power plant; it contributes about half to the all-out cost and causes about $47 \%$ of the annual energy losses. The performance of the heliostat field is characterized in terms of the optical efficiency which is the proportion of the net power consumed by the receiver to the power incident normally on the field. The optical losses from the heliostat field consider into account the losses, such as cosine, shadowing and blocking, because of the field layout design. Most of the heliostat field is designed in radial staggered pattern. This course of action guarantees that no heliostat is transferred before another heliostat in adjacent rings because reflected beam from the heliostats can pass legitimately to the receiver between adjacent neighbors [1].

A few studies have uncovered that the radial stagger arrangement is the most productive for a given land area as it chops down the land utilization and atmospheric attenuation losses. Hence, it adds to the most catalyst distribution for heliostat fields. Lipps et al. presented staggered and cornfield configurations, but the conclusion of this work shows that the radial staggered configuration creates progressively productive layouts because of the lower losses identified with shadowing and blocking. Collado et al. [2] introduced an improved form of this algorithm that thought about the spacing between the rings of a zone constant. So as to diminish the shadowing and blocking losses, and to keep the minimum distance for mechanical requirement, the calculation proposed a parameter 'desp' to characterize the minimum distance between the heliostats. For this calculation, the initial step is the count of the parameters that characterize each of the zones in the field (azimuth spacing, the radius of the first 
row in the zone, number of heliostats per row and the number of rows in the zone). Presently, radial staggered type layout is utilized to design real heliostat field.

The structure of subsequent sections is as follows. Design calculation of heliostat field layout is presented in Section 2 . In Section 3, the calculation of the optical efficiency is described. The simulation results are given in Section 4. Finally, conclusions are attracted in Section 5 .

\section{DESIGN PROCEDURE OF HELIOSTAT FIELD LAYOUT}

The performance of heliostat field characterized as far as the optical efficiency. Most heliostat field layout plans take a radial stagger pattern example as per the way that each heliostat can move unreservedly and the heliostats remaining between two heliostats of the front ring lessen the blocking. Most ways to deal with improve the layout structure of the heliostat field depend on the radial stagger concept. In this subsection, the method to send a radial staggered heliostat field and to calculate different parameters, for example, the characteristic diameter, radial spacing, azimuthal spacing, number of rows and number of heliostats are displayed. The variables used to define the heliostat are illustrated in Fig. 1 [3].

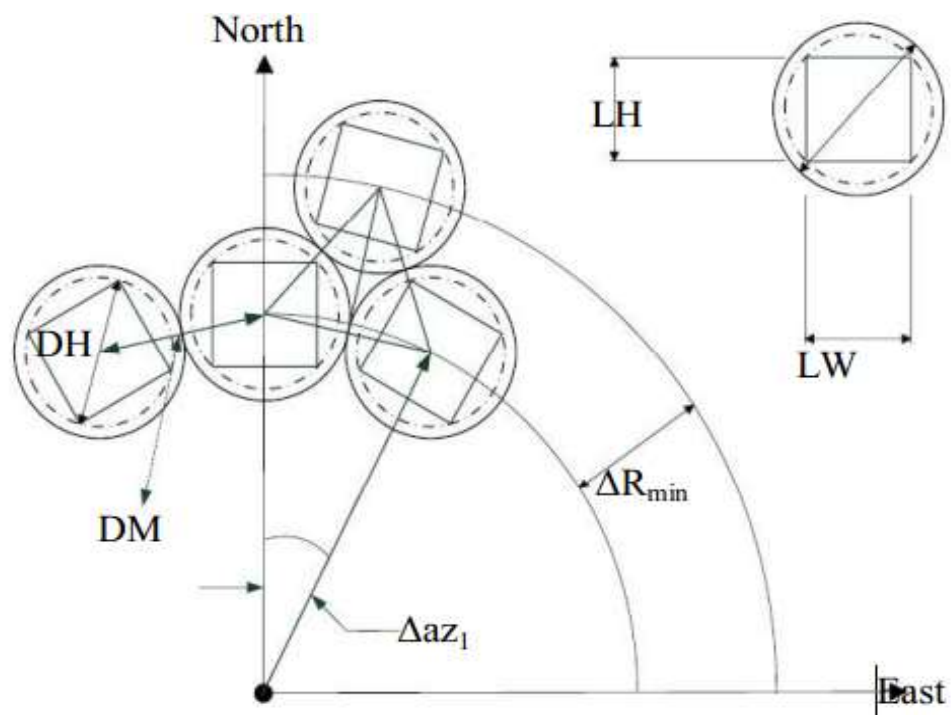

Fig. 1 Fundamental definitions in the heliostat field [4]

\subsection{The Characteristic Diameter}

The characteristic diameter is the distance between the center of the adjacent heliostats, and it very well may be determined with the following equation [4]:

$\mathrm{DM}=\sqrt{\left(1_{\mathrm{w}}^{2}+\mathrm{l}_{\mathrm{h}}^{2}\right)}+\operatorname{desp}$

where DM is the characteristic diameter of the heliostat in $\mathrm{m}, \mathrm{l}_{\mathrm{w}}$ and $\mathrm{l}_{\mathrm{h}}$ are the width and height of the heliostat in $\mathrm{m}$, and desp is any additional separation distance between adjacent heliostats.

\subsection{The Radial and Azimuth Spacing}

The minimum radius of the heliostats ought to guarantee that adjacent heliostats do not occur mechanical collisions, and is given as [5]:

$$
\Delta \mathrm{R}_{\min }=\mathrm{DM} \times \cos 30^{\circ}
$$

In light of the quantity of heliostats in each row of the first zone, radial distance from the tower to the first row of the heliostats $\left(\mathrm{R}_{1}\right)$ can be determined as follows:

$$
\mathrm{R}_{1}=\mathrm{Nhel}_{1} \frac{\mathrm{DM}}{2 \pi}
$$

where $\mathrm{Nhel}_{1}$ is the number of heliostats within each row of the first zone. The azimuth angular spacing for the first zone of the heliostat field can be determined by [5]: 
$\Delta_{\mathrm{az}_{1}}=2 \sin ^{-1} \frac{\mathrm{DM}}{2 \pi}$

where $\Delta \mathrm{az}_{1}$ is the azimuth angular spacing for the first zone in rad.

Because of the radially staggered configuration, the distance between two neighboring mirrors (length in meters) relies upon their radial distance from the tower. Thusly, as the rows escape from the tower, the space between their heliostats increments. Eventually, spaces between the mirrors become more noteworthy than DM making it conceivable to put extra mirrors between two connecting mirror in a similar row. A zone is viewed as finished as the possibility of the expansion of extra mirrors inside its last row. Consequently, the azimuth angular spacing for the $\mathrm{i}^{\text {th }}$ zone can be resolved by [5]:

$\Delta_{\mathrm{az}_{\mathrm{i}}}=\frac{\Delta_{\mathrm{az}_{1}}}{2^{\mathrm{i}-1}}$

where $\Delta \mathrm{az}_{\mathrm{i}}$ is the azimuth angular spacing for the $\mathrm{i}^{\text {th }}$ zone in rad.

The radial distance from the tower to the first row of the $\mathrm{i}^{\text {th }}$ zone is determined with the end goal that [6]:

$\mathrm{R}_{\mathrm{i}}=2^{\mathrm{i}-1} \frac{\mathrm{DM}}{\Delta_{\mathrm{az}}}$

where $R_{i}$ is the radius of the first row for the $i_{\text {th }}$ zone in $m$.

Utilizing Equations 2 through 6, the radial and azimuth angular spacing for various zones from the tower can be determined.

\subsection{Number of Rows and Heliostats}

The number of rows for the $\mathrm{i}^{\text {th }}$ zone is determined by [6]:

Nrow $_{i}=\frac{R_{i+1}-R_{i}}{\Delta R_{\min }}$

where Nrow $_{\mathrm{i}}$ is the number of rows of heliostats for $\mathrm{i}^{\text {th }}$ zone of the field.

The number of heliostats for each row within the $i^{\text {th }}$ zone is determined as [6]:

Nhel $_{i}=\frac{2 \pi}{\Delta \mathrm{az}_{\mathrm{i}}}$

where $\mathrm{Nhel}_{\mathrm{i}}$ is the number of heliostats in each row within the $\mathrm{i}^{\mathrm{th}}$ zone.

\section{CALCULATION OF THE OPTICAL EFFICIENCY}

The optical efficiency, $\eta_{\text {opt }}$ measures the energy loss of the heliostat field. In general, the optical efficiency of the heliostat field layout is calculated by [6]:

$\eta_{\mathrm{opt}}=\eta_{\mathrm{at}} \times \eta_{\mathrm{ref}} \times \eta_{\mathrm{s} \& \mathrm{~b}} \times \eta_{\mathrm{cos}}$

where $\eta_{\text {at }}$ is atmospheric attenuation efficiency, $\eta_{\text {ref }}$ is mirror reflectivity, $\eta_{\mathrm{s} \& b}$ is shadowing and blocking efficiency and $\eta_{\text {cos }}$ is cosine efficiency. Among them, the value of mirror reflectivity depending on the heliostat reflective rate can be set to a constant $\left(\eta_{\text {ref }}=0.88\right.$ is embraced here), the others are impacted by the heliostat field setup, the height of the receiver or different components related. .Therefore, four sorts of efficiency with the exception of $\eta_{\text {ref }}$ need to be computed to decide the optical efficiency.

\subsection{The Atmospheric Attenuation Efficiency, $\eta_{\mathrm{at}}$}

The impact that a portion of the energy of the reflected rays are dispersed and consumed by the atmosphere is referred as atmospheric attenuation loss. The atmospheric transmission efficiency emphatically relies upon the climate condition and the distance between the heliostat and the receiver. For a visual distance of about $40 \mathrm{~km}$, the atmospheric transmission efficiency can be determined basically as an element of the distance between the heliostat and the receiver in meters as follow [7].

If $\mathrm{d} \leq 1000 \mathrm{~m}$,

$\eta_{\mathrm{at}}=0.99321-0.0001176 \mathrm{~d}+1.97 \times 10^{-8} \mathrm{~d}^{2}$

If $\mathrm{d}>1000 \mathrm{~m}$

$\eta_{\text {at }}=\mathrm{e}^{-0.0001106 \mathrm{~d}}$

where $d$ is the distance between the heliostat and the receiver. The atmospheric attenuation efficiency $\left(\eta_{\text {at }}\right)$ can be determined by utilizing equations (10) and (11). 


\subsection{The Shadowing and Blocking Efficiency}

Shadowing happens when a shadow is thrown by a heliostat onto a neighboring heliostat. Accordingly, all the incident solar flux doesn't arrive at the reflector. Blocking losses happen when a heliostat's reflected flux is obstructed by a heliostat in the foreground. The point-by-point, time subordinate calculations of shadowing and blocking require complex methodology including intricate ray tracing of individual heliostats. $\left(\eta_{\mathrm{s} \& b}=0.944\right.$ is received here). Therefore, typical yearly average is utilized. Annual average shadowing and blocking loss is about $5.6 \%$ [7].

\subsection{The Cosine Efficiency}

The most significant loss in the heliostat field is because of the angle between the incident solar beam radiation, and a vector ordinary to the outside of the heliostat which is known as the cosine impact. In this way, it relies upon both sun and heliostat positions.

\section{A. Solar position}

The solar position is significant in light of the fact that the sun is changing hourly during a day and every day during the year, so it is important to show the solar coordinate systems during the year through solar angles.

The solar declination is calculated by [8]:

$\delta_{\mathrm{S}}=23.45 \sin \left(\frac{360}{365}(284+\mathrm{N})\right)$

where $\mathrm{N}$ is the number of days during the year starting from the $1^{\text {st }}$ of January.

The solar hour angle $\left(\mathrm{h}_{\mathrm{s}}\right)$ is calculated using the following equation [8].

$\mathrm{h}_{\mathrm{s}}=(\mathrm{AST}-12) \times 15^{\circ}$

where AST is the apparent solar time and is calculated by:

$\mathrm{AST}=\mathrm{LST}+\mathrm{ET}+4(\mathrm{SL}-\mathrm{LL})$

Where LST is the local standard time, SL is the standard longitude, LL is the local longitude and ET is the equation of time.

Equation of the time is calculated by:

$\mathrm{ET}=\frac{9.87 \sin (2 \mathrm{~B})-7.53 \cos (\mathrm{B})-1.5 \sin (\mathrm{B})}{60}$

Where $\mathrm{B}=(\mathrm{N}-1) \frac{360}{364}$

The solar altitude angle $\left(\alpha_{\mathrm{s}}\right)$ is computed with the equation (16), where all the parameters are calculated and defined previously above [9]:

$\alpha_{\mathrm{s}}=\sin ^{-1}\left[\cosh \left(\mathrm{h}_{\mathrm{s}}\right) \cdot \cos \left(\delta_{\mathrm{s}}\right) \cdot \cos \left(\phi_{\mathrm{lat}}\right)+\sin \left(\delta_{\mathrm{s}}\right) \cdot \sin \left(\phi_{\mathrm{lat}}\right)\right.$

The solar zenith angle $\left(\theta_{\mathrm{z}}\right)$ is obtained as an element of $\alpha_{\mathrm{s}}[9]$.

$\theta_{\mathrm{z}}=90^{\circ}-\alpha_{\mathrm{s}}$

The solar azimuth angle $\left(\varphi_{\mathrm{s}}\right)$ is calculated by considering a solar azimuth factor $\left(\varphi^{\prime}\right)$ and the solar hour angle conditions [9].

$\varphi^{\prime}=\sin ^{-1}\left(\frac{\cos \delta_{\mathrm{S}} \times \sinh _{\mathrm{S}}}{\sin \theta_{\mathrm{Z}}}\right)$

The solar hour angle conditions are [9]:

If $\cosh _{\mathrm{s}} \geq\left(\frac{\tan \delta_{\mathrm{s}}}{\tan \varphi_{\text {lat }}}\right) \quad \varphi_{\mathrm{s}}=180^{\circ}-\varphi^{\prime}$

Else $\cosh \mathrm{s}_{\mathrm{s}} \leq\left(\frac{\tan \delta_{\mathrm{S}}}{\tan \varphi_{\text {lat }}}\right) \quad \varphi_{\mathrm{s}}=180^{\circ}+\varphi^{\prime}$

The surface azimuth angle ( $\left.\varphi_{\text {surf }}\right)$ can be obtained by [9]:

If $\varphi_{\mathrm{s}}-\varphi^{\prime}>0, \quad \varphi_{\text {surf }}=\varphi^{\prime}+90^{\circ}$

Else $\varphi_{\mathrm{s}}-\varphi^{\prime}<0, \quad \varphi_{\text {surf }}=\varphi^{\prime}-90^{\circ}$ 


\section{B. Heliostat position}

The solar altitude angle of the tower receiver for each heliostat $\left(\alpha_{t r}\right)$ which is defined by the tower height $\left(H_{t}\right)$, the height of each heliostat $\left(\mathrm{H}_{\mathrm{h}}\right)$ and the distance of each heliostat from the tower base $(\mathrm{R})$ is calculated and illustrated in Fig. 2 [10].

$\alpha_{\mathrm{tr}}=\tan ^{-1}\left(\frac{\mathrm{H}_{\mathrm{t}}-\mathrm{H}_{\mathrm{h}}}{\mathrm{R}}\right)$

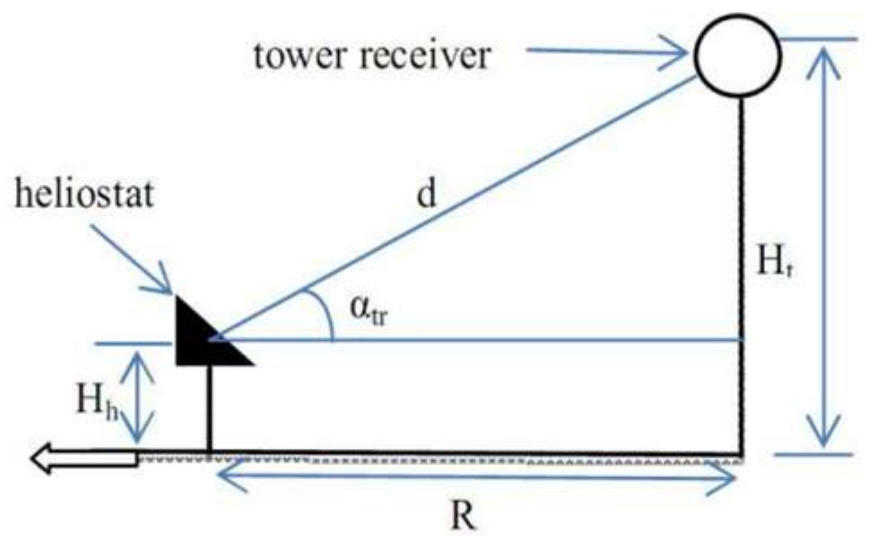

Fig. 2 Solar altitude angle of tower receiver [10]

For calculating the distance of each heliostat from the tower receiver (d), the Pythagorean Theorem is used.

$\mathrm{d}=\sqrt{\mathrm{R}^{2}+\left(\mathrm{H}_{\mathrm{t}}-\mathrm{H}_{\mathrm{h}}\right)^{2}}$

In order to reflect the incident radiation on each heliostat and direct it to the tower receiver, the rotation angle of them is calculated by [9]:

$\beta_{\mathrm{hs}}=\frac{\alpha_{\mathrm{tr}}-\alpha_{\mathrm{s}}}{2}$

The solar incidence angle on each heliostat $\left(\theta_{\mathrm{s}}\right)$ is calculated by [10]:

$\theta_{\mathrm{s}}=\cos ^{1}\left[\left(\sin \phi_{\text {lat }} \cdot \sin \delta_{\mathrm{s}} \cdot \cos \beta_{\mathrm{hs}}\right)\left(\cos \phi_{\mathrm{lat}} \cdot \sin \delta_{\mathrm{s}} \cdot \sin \beta_{\mathrm{hs}} \cdot \cos \varphi_{\mathrm{surf}}\right)+\left(\cos \phi_{\text {lat }} \cdot \cos \delta_{\mathrm{s}} \cdot \cos \mathrm{s}_{\mathrm{s}} \cdot \cos \beta_{\mathrm{hs}}\right)+\right.$

$\left.\left(\sin \phi_{\text {lat }} \cdot \cos \delta_{\mathrm{s}} \cdot \cosh \mathrm{s}_{\mathrm{s}} \cdot \sin \beta_{\mathrm{hs}} \cos \varphi_{\text {surf }}\right)+\left(\cos \delta_{\mathrm{s}} \cdot \sinh \mathrm{s}_{\mathrm{s}} \cdot \sin \beta_{\mathrm{hs}} \cdot \sin \varphi_{\text {surf }}\right)\right]$

The formula for calculating the receiving angle of the receiver can be calculated as follows [11].

$\theta_{\mathrm{R}}=\cos ^{-1}\left(\frac{\mathrm{d}}{\mathrm{H}_{\mathrm{rec}}}\right)$

where $\mathrm{d}$ is the diameter of reflected spot and $\mathrm{H}_{\text {rec }}$ is the height of the receiver.

The angle between reflected sun rays and the vertical direction $\left(\lambda_{\mathrm{s}}\right)$ is

$\lambda_{\mathrm{S}}=90^{\circ}-\theta_{\mathrm{R}}$

After getting all the solar angles needed and defining the solar field layout, the cosine efficiency of the heliostat field is calculated by:

$\eta_{\cos }=\frac{\sqrt{2}}{2}\left(\sin \alpha_{\mathrm{s}} \cos \alpha_{\mathrm{S}}-\cos \left(\varphi_{\text {surf }}-\varphi_{\mathrm{S}}\right) \cos \alpha_{\mathrm{s}} \sin \lambda_{\mathrm{S}}+1\right)^{0.5}$

Substituting equations (12) through (28), the cosine efficiency can be calculated. The overall cosine efficiency of the heliostat field layout is 0.9006 .

\subsection{Receiver Sizing and Tower Height Design}

Receiver sizing is done in light of the reasonable flux on the receiver. The allowable flux on the receiver relies on the receiver material and the type of HTF. Generally, the allowable peak flux for molten salt receivers built with Stainless steel material is $0.83 \mathrm{MW} / \mathrm{m}^{2}$ and one-half to one-third of the peak flux is selected as an average flux [11]. There are two basic types of receivers: external and cavity. In case of external receivers, the output geometry design includes diameter and height of the receiver. In order to design the outer geometry, the parameter receiver aspect ratio, $A R$ (height, $\mathrm{H}_{\mathrm{rec}}$ to diameter, $\mathrm{D}_{\mathrm{rec}}$ ratio) is introduced. Generally, for an external receiver, the aspect ratio lies between 1 to 2 . In this model, the default value of receiver aspect ratio is set as 1.5 . The area of the receiver $\mathrm{A}_{\text {rec }}$ can be derived as:

$\mathrm{A}_{\text {rec }}=\frac{\mathrm{Q}_{\text {rec, in }}}{\mathrm{q}_{\text {avg,flux }}}$ 
where $\mathrm{q}_{\mathrm{avg}, \mathrm{flux}}$ is allowable average flux of the receiver

$\mathrm{A}_{\text {rec }}=\pi \times \mathrm{D}_{\text {rec }} \times \mathrm{H}_{\text {rec }} \times \pi / 2$

The factor, $\pi / 2$ used to take into account curvature of the tubes in the receiver. The above equation can be reformulated regarding the receiver aspect ratio and the geometry can be calculated as:

$$
\begin{aligned}
& \mathrm{D}_{\text {rec }}=\sqrt{\frac{\mathrm{A}_{\text {rec }}}{\pi \times \mathrm{AR} \times \pi / 2}} \\
& \mathrm{~A}_{\text {rec }}=\mathrm{AR} \times \mathrm{D}_{\text {rec }}
\end{aligned}
$$

The tower height for surround fields can be calculated as below:

$$
\begin{gathered}
\mathrm{H}_{\text {tower,min }}=36.30075+\left(0.3013896 \times \mathrm{Q}_{\text {rec,in }}\right)- \\
\left(0.1004369 \times 10^{-3} \times \mathrm{Q}_{\text {rec,in }}{ }^{2}\right) \\
\mathrm{H}_{\text {tower,max }}=54.91579+\left(0.3070526 \times \mathrm{Q}_{\text {rec,in }}\right)- \\
\left(0.1039793 \times 10^{-3} \times \mathrm{Q}_{\text {rec,in }}{ }^{2}\right) \\
\mathrm{H}_{\text {tower }}=\frac{\mathrm{H}_{\text {tower,min }}+\mathrm{H}_{\text {tower,max }}}{2}
\end{gathered}
$$

\subsection{Design Management of Field Layout}

The coordinates of the chose location for this plant are $21.959^{\circ}$ (latitude) and $96.089^{\circ}$ (longitude), which is a city called Mandalay, Myanmar. The procedures are as follows:

1. The height and width of the heliostat is identified and then the tower height and the characteristic diameter of the heliostat with various separation distances are calculated.

2. The number of heliostats in each row of the first zone is adopted and the number of heliostats in each row of the $i^{\text {th }}$ zone is computed by using equation 2 through 8 .

3. Depend on the distance between the heliostat and receiver, the attenuation efficiency is calculated in equation $10 \& 11$.

4. The cosine efficiency depend on both sun and heliostat position. The solar declination angle, the azimuth angle and zenith angle are calculated.

5. The optical efficiency of heliostat field layout is evaluated by using equation 9 .

\section{RESULTS}

The layout contains three zones and each zone is distinguished with different color in Fig.3. The first row contains 19 heliostats. The field density lessens with each zone by moving outward away from the center of the field (tower). The first zone consists of 57 heliostats spread equally in 3 rows. The second zone includes 228 heliostats distributed equally within 6 rows. Finally, the third zone contains 380 heliostats distributed equally within 5 rows. In total, this design field layout contains 14 rows and 665 heliostats around a $62 \mathrm{~m}$ tall tower and each heliostat has a $121 \mathrm{~m}^{2}$ reflecting area.

For desp $=0.2$, 
International Journal of Advances in Scientific Research and Engineering (ijasre), Vol 5 (11), November-2019

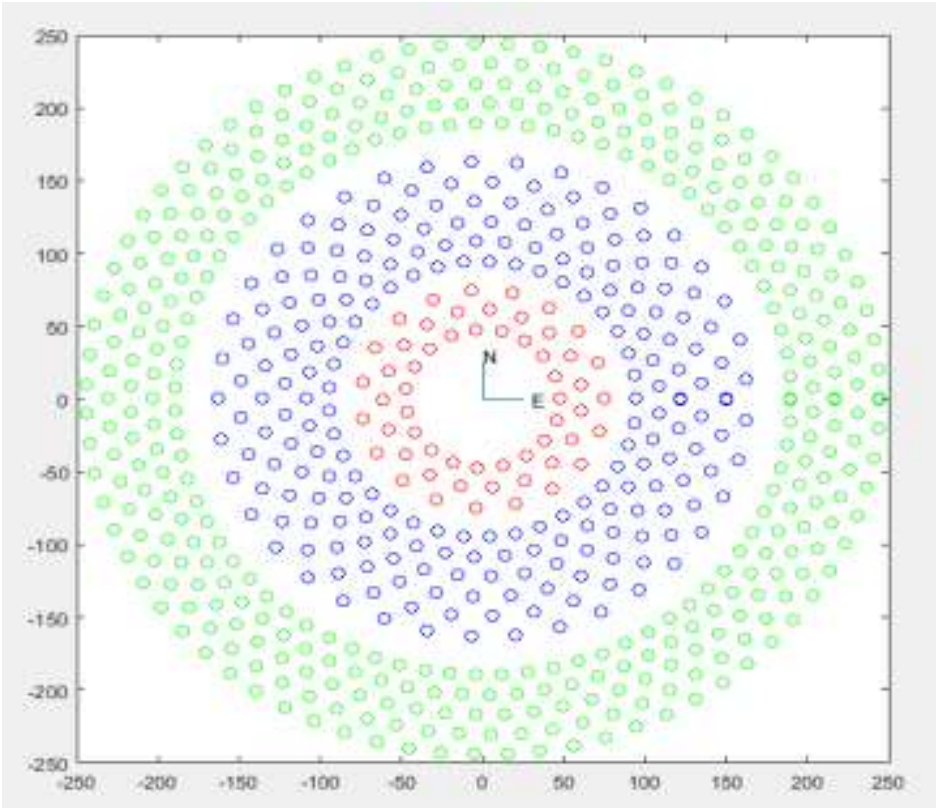

Fig. 3 Radial staggered pattern of the heliostat field layout $(\operatorname{desp}=0.2)$

Table 1 RESULTS OF RELATED VALUES FOR LAYOUT (desp=0.2)

\begin{tabular}{|c|c|c|c|c|}
\hline Ring No. & $\mathbf{R}(\mathbf{m})$ & $\boldsymbol{\alpha}_{\text {tr }}\left(^{\circ}\right)$ & $\mathbf{d}(\mathbf{m})$ & $\boldsymbol{\eta}_{\text {at }}(\boldsymbol{\%})$ \\
\hline 1 & 47.6463 & 48.5768 & 72.0151 & 0.9848 \\
\hline 2 & 61.2917 & 41.3811 & 81.6864 & 0.9837 \\
\hline 3 & 74.9371 & 35.7767 & 92.3665 & 0.9825 \\
\hline 4 & 94.8550 & 29.6524 & 109.1489 & 0.9806 \\
\hline 5 & 108.5004 & 26.4593 & 121.1955 & 0.9792 \\
\hline 6 & 122.1458 & 23.8500 & 133.5500 & 0.9779 \\
\hline 7 & 135.7912 & 21.6862 & 146.1344 & 0.9764 \\
\hline 8 & 149.4366 & 19.8677 & 158.8940 & 0.9750 \\
\hline 9 & 163.0820 & 18.3208 & 171.7898 & 0.9736 \\
\hline 10 & 189.7100 & 15.8887 & 197.2458 & 0.9708 \\
\hline 11 & 203.3554 & 14.8714 & 210.4030 & 0.9693 \\
\hline 12 & 217.0008 & 13.9740 & 223.6188 & 0.9679 \\
\hline 13 & 230.6462 & 13.1770 & 236.8833 & 0.9665 \\
\hline 14 & 244.2916 & 12.4646 & 250.1887 & 0.9650 \\
\hline & & & & \\
\hline
\end{tabular}

For desp $=1$, 
International Journal of Advances in Scientific Research and Engineering (ijasre), Vol 5 (11), November-2019

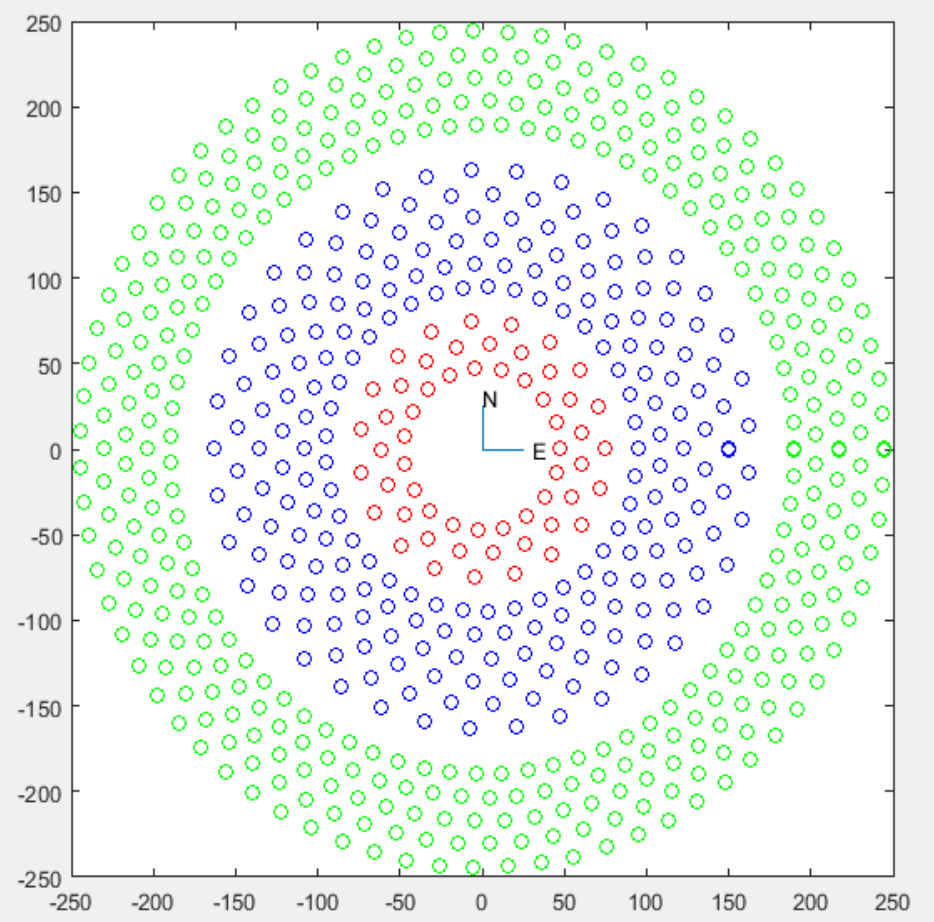

Fig. 4 Radial staggered pattern of the heliostat field layout (desp=1)

Table 2 RESULTS OF RELATED VALUES FOR LAYOUT (desp=1)

\begin{tabular}{|c|c|c|c|c|}
\hline Ring No. & $\mathbf{R}(\mathbf{m})$ & $\boldsymbol{\alpha}_{\text {tr }}\left(^{\circ}\right)$ & $\mathbf{d}(\mathbf{m})$ & $\boldsymbol{\eta}_{\text {at }}(\mathbf{\%})$ \\
\hline 1 & 50.0655 & 47.1652 & 73.6380 & 0.9847 \\
\hline 2 & 64.4037 & 39.9785 & 84.0466 & 0.9835 \\
\hline 3 & 78.7419 & 34.4417 & 95.4793 & 0.9822 \\
\hline 4 & 99.6711 & 28.4480 & 113.3593 & 0.9801 \\
\hline 5 & 114.0093 & 25.3444 & 126.1512 & 0.9787 \\
\hline 6 & 128.3475 & 22.8181 & 139.2447 & 0.9772 \\
\hline 7 & 142.6858 & 20.7294 & 152.5622 & 0.9757 \\
\hline 8 & 157.0240 & 18.9779 & 166.0498 & 0.9742 \\
\hline 9 & 171.3622 & 17.4908 & 179.6691 & 0.9727 \\
\hline 10 & 199.3422 & 15.1571 & 206.5268 & 0.9698 \\
\hline 11 & 213.6804 & 14.1825 & 220.3981 & 0.9682 \\
\hline 12 & 228.0186 & 13.3235 & 234.3256 & 0.9667 \\
\hline 13 & 242.3569 & 12.5610 & 248.2999 & 0.9652 \\
\hline 14 & 256.6951 & 11.8799 & 262.3135 & 0.9637 \\
\hline
\end{tabular}

For desp=5, 
International Journal of Advances in Scientific Research and Engineering (ijasre), Vol 5 (11), November-2019

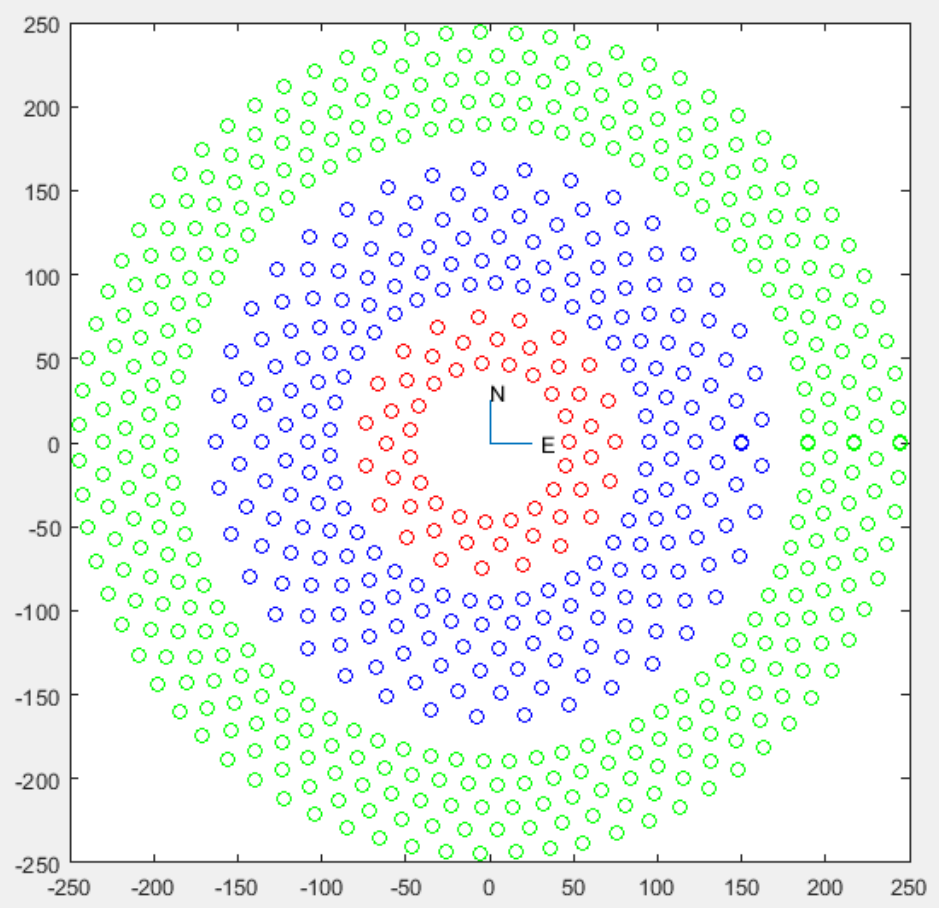

Fig. 5 Radial staggered pattern of the heliostat field layout $(\operatorname{desp}=5)$

Table 3 RESULTS OF RELATED VALUES FOR LAYOUT (desp=5)

\begin{tabular}{|c|c|c|c|c|}
\hline Ring No. & $\mathbf{R}(\mathbf{m})$ & $\boldsymbol{\alpha}_{\text {tr }}\left(^{\circ}\right)$ & $\mathbf{d}(\mathbf{m})$ & $\boldsymbol{\eta}_{\text {at }}(\mathbf{\%})$ \\
\hline 1 & 62.1612 & 40.9811 & 82.3409 & 0.9837 \\
\hline 2 & 79.9636 & 34.0315 & 96.4892 & 0.9820 \\
\hline 3 & 97.7659 & 28.9136 & 111.6878 & 0.9803 \\
\hline 4 & 123.7516 & 23.5744 & 135.0202 & 0.9777 \\
\hline 5 & 141.5539 & 20.8809 & 151.5041 & 0.9758 \\
\hline 6 & 159.3562 & 18.7196 & 168.2569 & 0.9740 \\
\hline 7 & 177.1585 & 16.9518 & 185.2057 & 0.9721 \\
\hline 8 & 194.9608 & 15.4816 & 202.5089 & 0.9702 \\
\hline 9 & 212.7632 & 14.2412 & 219.5089 & 0.9683 \\
\hline 10 & 247.5031 & 12.3079 & 253.3255 & 0.9647 \\
\hline 11 & 265.3054 & 11.5048 & 270.7452 & 0.9628 \\
\hline 12 & 283.1078 & 10.7989 & 288.2117 & 0.9610 \\
\hline 13 & 300.9101 & 10.1738 & 305.7170 & 0.9591 \\
\hline 14 & 318.7124 & 9.6164 & 323.2547 & 0.9573 \\
\hline
\end{tabular}


The radial staggered pattern of the heliostat field layout for desp $=0.2$ is shown in Fig. 3 and the attenuation efficiency for desp $=0.2$ is described in Table 1. For desp=1, the radial staggered pattern of the heliostat field layout is illustrated in Fig. 4 and results of related values for layout is described in Table 2. For desp=5, the layout of radial staggered pattern for heliostat field is shown in Fig. 5 and related values are tabulated in Table 3.

Table 4 RESULTS OF OPTICAL EFFICIENCY

\begin{tabular}{|c|c|c|c|c|}
\hline Time & $\begin{array}{c}\text { Separation } \\
\text { Distance(des) }\end{array}$ & $\begin{array}{c}\text { Attenuation } \\
\text { Efficiency }\end{array}$ & Optical & Field Area $\left(\mathbf{m}^{2}\right)$ \\
\hline 9 a.m & 0.2 & 0.7531 & 0.5634 & 70189.041 \\
\hline & 1 & 0.7429 & 0.5558 & 75202.544 \\
\hline 1 p.m & 5 & 0.7136 & 0.5339 & 95256.556 \\
\hline & 0.2 & 0.9752 & 0.7295 & 70189.041 \\
\hline & 1 & 0.9615 & 0.7193 & 75202.544 \\
\hline 5 p.m & 5 & 0.9406 & 0.7037 & 95256.556 \\
& 0.2 & 0.4591 & 0.3435 & 70189.041 \\
\hline & 1 & 0.4426 & 0.3311 & 75202.544 \\
\hline
\end{tabular}

The separation distance of attenuation efficiency is less; the optical efficiency of the field layout is more. The optical efficiency and attenuation efficiency in the heliostat field layout with various separation distances at 9 a.m, 1 p.m and 5 p.m are shown in Table 4. Among them, the optical efficiency of the heliostat field layout at 1 p.m is higher than other times.

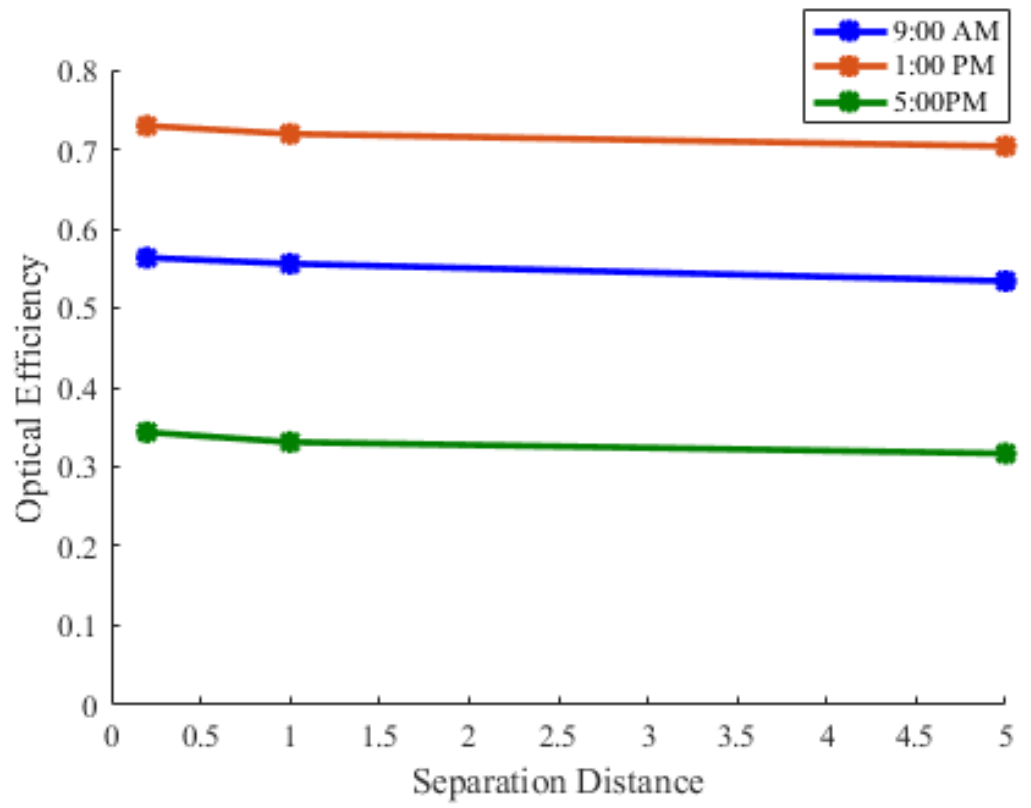

Fig. 6 Optical efficiency with various separation distance at 9 a.m, 1 p.m and 5 p.m

The optical efficiency with various separation distance at 9 a.m, 1 p.m and 5 p.m is illustrated in Fig.6. The separation distance between each ring is increased, the optical efficiency of the field layout is decreased. 


\section{CONCLUSIONS}

In order to calculate the optical efficiency of a solar power plant, a radial stagger pattern for the heliostat field layout was proposed in this paper. By using this pattern, the heliostat can be placed with a higher optical efficiency as well as a faster speed due to the way that each heliostat could move openly and the heliostats remaining between two heliostats of the first ring decrease the shadowing and blocking. A mathematical code was created in MATLAB, which generates a heliostat field effectively to calculate optical efficiency. According to the result of layout design, the separation distance of the attenuation efficiency is less; the optical efficiency of the field layout is more. The separation distance of the attenuation efficiency is increased; the heliostat field area of the layout is also increased.

\section{ACKNOWLEDMENT}

The author would like to express grateful thanks to all her teachers from Department of Electrical Power Engineering, Mandalay Technological University, for their valuable guidance. The author greatly expresses to her thanks to all persons whom will concern to support in preparing this paper. Finally, the author is deeply grateful to her parents who specially offered strong moral and physical support, care and kindness.

\section{REFERENCES}

1. Chen, Y.T., Kribus, A., Lim, B.H., Lim, C.S., Chong, K.K., Karni, J., Buck, R., Pfahl, A., Bligh, T.P., 2004. Comparison of two sun tracking methods in the use of a heliostat field. Journal of Solar Energy Engineering 126 (1), 638-644

2. Chong, K.K, M.H. Tan (2011). Range of motion study for two different sun-tracking techniques in the application of heliostat field

3. Francisco J Collado,Jesus Guallar, "Campo: Generation of regular heliostat field”.Renewable Energy, vol. 46,pp.4959,2012

4. Maimoon Atif and Enhad A.AI-Sulaiman, "Development of a mathematical model for optimization of a heliostat field layout using differential evoluation method", International Journal of Energy Research, 2015

5. Mohammad Saghafifar, "Thermo-Economic Optimization of Hybird Combined Power Cycles using Heliostat Field Collector" Master Thesis of American University of Sharjah College of engineering, 2016

6. Saeb M. Besarati and D. Yogi Goswami, "A computationally efficient method for the design of the heliostat field for solar power tower plant", Renewable Energy, vol. 69, pp. 226-223, 2014

7. Chao Shen. Et al., "Modelling and simulation of solar radiation data processing with Simulink", Simulation Modelling Practice and Theory, pp.. 721-735,2008

8. Bauer, T., et al.: Overview of Molten Salt Storage Systems and Material Development for Solar Thermal Power Plants, Technical report, German Aerospace Center (DLR) Institute of Technical Thermodynamics, (2012)

9. Xiudong Wei, et al, "A new method for the design of the heliostat field layout for solar tower power plant", Renewable Energy, vol.35, pp.1970-1975, 2010

10. Yingxue Yao, Yeguang Hub and Shengdong Gao, "Heliostat field layout methodology in central receiver systems based on efficiency-related distribution", Solar energy, vol.17,pp. 114-124,2015

11. William B Stine and Raymond W Harrigan, "Solar energy fundamentals and design",1985 